\title{
Contributing Factors for Perceived Satisfaction with Nursing Care among Inpatients in General Wards
}

\author{
Mamta Koirala, ${ }^{a}$ Mohan Laxmi Koirala ${ }^{\mathrm{b}}$
}

\begin{abstract}
:
Introduction: Patients' perceived satisfaction with quality of care may affects health outcomes. Patients who are satisfied with their nursing care are more likely to follow treatment and consequently to have better health outcomes. It encourages them to behave in a healthy way after discharge, and positive rating of service quality seems to be correlated with no hesitation about revisiting the same hospital ward in time of need. This study was done to identify the contributing factors for perceived satisfaction with nursing care among inpatients in general wards in Lumbini Medical College. Methods: A descriptive cross sectional study was conducted in Lumbini Medical College Teaching Hospital throughout the month of August, 2015. A total of 60 heterogeneous study population from three different wards (Medical, Surgical, and Orthopedics), who gave consent for participation, were included using non-probability convenient sampling technique. Nepalese version of Newcastle Satisfaction with Nursing Scale (NSNS) was used to measure the satisfaction score. Results: There were a total of 60 respondents with mean age of 30.08 years $(S D=9.72)$. Male, duration of hospital stay, and number of hospital stay had a significant relation with the satisfaction score when calculated individually. However, the relationship was not significant when adjusted for other variables by linear regression. Conclusion: Majority of respondents were satisfied with the quality of nursing care. Male, duration of hospital stay, and number of hospital admission had a significant relation with the satisfaction score when calculated individually. The nurses should know the factors influencing patients' satisfaction and work on those to improve the quality of nursing care.
\end{abstract}

Keywords: patient satisfaction • nursing care $\bullet$ quality of health care $\bullet$ inpatients

\section{INTRODUCTION:}

There has been increasing interest in patients' satisfaction with nursing care in the past few decades. Patient satisfaction with nursing care is considered an important factor in explaining patients' perceptions of service quality. ${ }^{1}$ Patient satisfaction has been used as an indicator of quality services provided by health care personnel. The most

\footnotetext{
a - Lecturer, College of Nursing

Lumbini Medical College Teaching Hospital, Palpa, Nepal

b - Nursing Officer, United Mission Hospital, Palpa, Nepal

Corresponding Author:

Mamta Koirala

e-mail: koirala.mamta10@gmail.com
}

How to cite this article:

Koirala M, Koirala ML. Contributing factors for perceived satisfaction with nursing care among inpatients in general wards. Journal of Lumbini Medical College. 2015;3(2):34-7. doi: 10.22502/jlmc. v3i2.69 important predictor of patients' overall satisfaction with hospital care is particularly related to their satisfaction with nursing care. Patient satisfaction is defined as the extent of the resemblance between the expected quality of care and the actual received care. $^{2,3}$ Patient satisfaction is defined as the extent of the resemblance between the expected quality of care and the actual received care. Patient satisfaction with nursing care is important for any health care agency because nurses comprise the majority of health care providers and they provide care for patients 24 hours a day. ${ }^{4-7}$ Patients' satisfaction is now a critical variable in any calculation of quality or value and therefore in the assessment of corporate/individual accountability. It is a legitimate and important measure of quality of care. ${ }^{6,8,9}$

Health care providers in developing countries seem to be ignoring the importance of patients' perceptions of health services. ${ }^{10}$ Thus, a scarcity of literature made it difficult to find studies 
examining patients' satisfaction with nursing care in developing countries. Quality of health care in developing countries usually is defined by health care providers from technical perspective. Recent literature however, emphasizes the importance of patients' perspective in assessing quality of health care. ${ }^{10}$ It's the patient's perspective that increasingly is being viewed as a meaningful indicator of health services quality and may, in fact, represent the most important perspective. ${ }^{11}$

This study was done to identify the contributing factors for perceived satisfaction with nursing care among inpatients in general wards of Lumbini Medical College Teaching Hospital, a 700 bedded referral centre in a developing country.

\section{METHODS:}

A descriptive cross sectional study was conducted in Lumbini Medical College Teaching Hospital throughout the month of August, 2015. A total of 60 inpatients from three different departments (Medical, Surgical, and Orthopedics), who gave consent for participation and spent over night or more in the hospital wards were included using non-probability convenient sampling technique.

Newcastle Satisfaction with Nursing Scale (NSNS) was translated into its Nepalese version by repeated forward and backward translation till a panel of expert in Medical College was satisfied by the results. ${ }^{5,12}$ Pretesting was done by another panel of expert from the Nursing Department. This scale consists of 19 items and each item was to be scored on a five point Likert scale ranging from "very unsatisfied" carrying a value of one to "very satisfied" carrying a value of five.

All the respondents were detailed about the nature and objective of the study and they were insured confidentiality of the information and also were allowed to leave any questions unanswered, if they had any doubts or were uncomfortable. Then, they were asked to rate their degree of satisfaction on the scale. Demographic data were collected in the same setting. Data were entered into Microsoft Excel 2013 and then analyzed with SPSS 21. Results was presented as mean, standard deviation, frequency and percentage. Mean between variables was analyzed with t-test and correlation with Karl Pearson correlation coefficient. Linear regression was applied to evaluate relationship between variables adjusted for other variables.

\section{RESULTS:}

There were a total of 60 respondents with a mean age of $30.08 \mathrm{yr}(S D=9.72)$. Mean age of male was $31.06 \mathrm{yr}(S D=10.35)$ and female was 28.89 yr $(S D=8.93)$ and the difference was not significant ( $t=0.86, d f=58, p=0.4)$. Majority of them ( $n=24,40 \%$ ) were of age group of 30 to 40 years. A Pearson correlation coefficient was calculated for the relationship between participants age and satisfaction score. A weak negative correlation was found ( $r=-0.27, p=0.04)$ indicating a significant linear relationship between the two variables. Younger patients tend to be more satisfied with the nursing care.

There were $33(55 \%)$ male and $27(45 \%)$ female with $\mathrm{M}: \mathrm{F}$ ratio of 1.22:1. The mean score of satisfaction in male was $3.16(S D=0.11)$ and in female was $3.15(S D=0.13)$ and this difference was not significant $(t=0.3, d f=58, p=0.76)$.

There were $44(73.3 \%)$ literate participants and the remaining $16(26.7 \%)$ were illiterate. The mean score of satisfaction in literate was 3.14 $(S D=0.11)$ and in illiterate was $3.19(S D=0.13)$. This difference was not significant $(t=1.48, d f=58$, $p=0.15$ )

Mean hospital stay of the patients was 2.07 days $(S D=3.1)$ with range of one to nine days. Correlation between days of hospital stay and satisfaction score showed a negative significant linear relationship $(r=-0.32, p=0.01)$. Patients who stayed longer in hospital tend to be less satisfied with the nursing care. Other results are shown in Table 1.

Multi-linear regression was applied to estimate the relationship between several

Table 1: Some variables of the respondents.

\begin{tabular}{|cc}
\hline Respondents' variables & $\boldsymbol{n}(\boldsymbol{\%})$ \\
\hline Age & \\
\hline 10 to 20 years & $9(15 \%)$ \\
\hline 21 to 30 years & $22(36.7)$ \\
31 to 40 years & $24(40 \%)$ \\
\hline$>40$ years & $5(8.3 \%)$ \\
\hline Duration of hospitalization at LMCTH & $10(16.7 \%)$ \\
\hline$<2$ days & $36(60 \%)$ \\
\hline $2-7$ days & $14(23.3 \%)$ \\
\hline$>7$ days & \\
\hline Number of hospital admission & $46(76.7 \%)$ \\
\hline 1st admission & $14(23.3 \%)$ \\
\hline
\end{tabular}


independent variables with satisfaction score. Relationship between none of the variables was statistically significant with the satisfaction score when adjusted for other variables. The result is shown in Table 2.

Table 2: Adjusted coefficient of regression analysis

\begin{tabular}{|c|c|c|}
\hline Variables & $\begin{array}{c}\text { Adjusted } \\
\text { Coefficient }\end{array}$ & $p$ \\
\hline Age & -0.002 & 0.38 \\
\hline \multicolumn{3}{|l|}{ Gender } \\
\hline Male & Reference & \\
\hline Female & -0.011 & 0.72 \\
\hline \multicolumn{3}{|l|}{ Education } \\
\hline Illiterate & Reference & \\
\hline Literate & -0.058 & 0.08 \\
\hline Hospital stay & -0.031 & 0.26 \\
\hline \multicolumn{3}{|l|}{ Number of admission } \\
\hline First & Reference & Reference \\
\hline Second or more & 0.038 & 0.15 \\
\hline
\end{tabular}

\section{DISCUSSION :}

Patients' satisfaction is an important quality outcome indicator of health care in the hospital setting. The measurement of patients' satisfaction with nursing is particularly important since nursing service is often a primary determinant of overall satisfaction during a hospital stay. ${ }^{13}$ Moreover, satisfied patients usually trust their health care providers, and as a return they comply with medical and nursing orders. Eventually the patients' healing process is enhanced and at the same time, they disseminate their experiences to others which increase the number of patients who uses the services. If not satisfied, the opposite may happen. ${ }^{14}$

The finding of our study is in consistent with study done by Jafar A. et al. in Jordan and almost identical to another study done by Amerbyoun A. et al. in Iranian Military Hospitals. ${ }^{15,16}$ Majority of the respondents $(n=24,40 \%)$ in our study were of age group 30 to $40 \mathrm{yr}$ which is similar to the findings in other studies including the study conducted by Thulung BK. et al. in Tribhuwan University Teaching Hospital, Kathmandu, Nepal. ${ }^{15-18}$ While there was no significant correlation between gender and patient satisfaction in a study by Wallin et al., ${ }^{18}$ similar to our finding, another study by Ottosson et al. reported higher satisfaction among male than female. ${ }^{19}$ Moreover, these findings were also similar to that of Mustard et al. who worked for improving patients' satisfaction through the consistent use of scripting by the nursing staff and pointed out that demographic characteristics such as sex and race seem to be unimportant. ${ }^{20}$

Present study reveals that there is no significant relation between the education status of patients and their satisfaction score in contrast to that by Wallin et al. who reported that less educated patients had higher satisfaction. ${ }^{18}$ In that study, $87 \%$ of respondents, who were illiterate, were fully satisfied compared to $56 \%$ who had diploma and above. This finding is also similar to the study by Quinn et al. in which less educated patients tended to have higher satisfaction than the patients with higher education. ${ }^{21}$

In a study by Wallin et al., ${ }^{18}$ majority $(66.7 \%)$ of respondents who had not had a history of previous hospital admission were fully satisfied compared to $10 \%$ of those who were admitted previously at least once to hospital. In our study, we found comparable satisfaction score in these two group of patients.

\section{CONCLUSION:}

This study highlights the contributing factors that influence the patient's satisfaction with nursing care among inpatients. Male, duration of hospital stay, and number of hospital stay had a significant relation with the satisfaction score when calculated individually. The nurses should know the factors influencing patients' satisfaction and work on those to improve the quality of nursing care.

\section{REFERENCES:}

1. Comley AL, DeMeyer E. Assessing patient satisfaction with pain management through a continuous quality improvement effort. J Pain Symptom Manage. 2001;21(1):27-40.

2. Needleman J, Buerhans P, Mattke S, Stewart M, Zelevinsky K. Nurse-staffing levels and the quality of care in hospitals. N Engl J Med. 2002;346(22):1715-22.

3. Wagner D, Bear M. Patient satisfaction with nursing care: a concept analysis within a nursing framework. J Adv Nurs. 2009;65(3):692-701. doi: 10.1111/j.13652648.2008.04866.x.

4. Aiken LH, Clarke SP, Sloane DM, Sochalski J, Silber JH. Hospital nurse staffing and patient mortality, nurse burnout, and job dissatisfaction. JAMA. 2002;288(16):1987-93.

5. Walsh M, Walsh A. Measuring patient satisfaction with nursing care: Experience of using the Newcastle Satisfaction with Nursing Scale. J Adv Nurs. 1999;29(2);307-15. 
6. Lari MA, Tamburini M, Gray D. Patients' needs, satisfaction, and health related quality of life: Towards a comprehensive model. Health Qual Life Outcomes. 2004;2:32. doi: 10.1186/1477-7525-2-32.

7. Crow R, Gage H, Hampson S, Hart J, Kimber A, Storey $\mathrm{L}$, et al. The measurement of satisfaction with healthcare: implications for practice from a systematic review of the literature. Health Technol Assess. 2002;6(32):1-244.

8. Delbanco TL. Quality of care through the patient's eyes. BMJ. 1996;313(7061):832-33.

9. McGee HM. Patient Satisfaction Surveys: Are they useful as indicators of Quality of Care? J Health Gain. 1998;2:5-8.

10. Andaleeb SS. Service quality perceptions and patient satisfaction: a study of hospitals in a developing country. Soc Sci Med. 2001;52(9):1359-70.

11. O'Connor SJ, Shewchuk RM, Carney LW. The great gap. Physician's perceptions of patient service quality expectation fall short of reality. ,J Health Care Mark. 1994;14(2):32-9.

12. McColl E, Thomas L, Bond S. A study to determine patients' satisfaction with nursing care. Nurs Stand. 1996;10(52):348.

13. Fleischer S, Berg A, Zimmermann M, Wüste K, Behrens J. Nurse- patient interaction and communication: A systematicliterature review.JPublic Health. 2009;17(5):33953. doi:10.1007/s10389-008-0238-1.

14. Dahlberg K, Todres L, Galvin K. Lifeworld-led healthcare is more than patient-led care: an existential view of well being. Med Health Care Philos; 2009;12(3): 265-271. doi: 10.1007/s11019-008-9174-7.

15. Alhusban MA, Abualrub RF. Patients' satisfaction with nursing care in Jordan. J Nurs Manag. 2009;17(6):746-58. doi: 10.1111/j.1365-2834.2008.00927.x.

16. Ameryoun A, Pourtaghi G, Yahaghi E, Heidari S, Bahadori M, Ebrahimnia M, et al. Outpatient and Inpatients Services Satisfaction in Iranian Military Hospitals. Iran Red Crescent Med J. 2013;15(9);843-7. doi: 10.5812/ircmj.12665.

17. Gupta BS, Shrestha S, Thulung BK. Patient's perception towards quality nursing care .J Nepal Health Res Counc. 2014;12(27):83-7.

18. Wallin E, Lundgren PO, Ulander K. and Holstein CS. Does age, gender or educational background effect patient satisfaction with short stay surgery? 2000;8(2):79-88.

19. Ottosson B, Hallberg IR, Axelsson K, Loven L. Patients' Satisfaction with Surgical Care Impaired by Cuts in Expenditure and After Interventions to Improve Nursing Care at a Surgical Clinic. Int J Qual Health Care. 1997;9(1):43-53.

20. Mustard LW. Improving patient satisfaction through the consistent use of scripting by the nursing staff. JONAS Healthc Law Ethics Regul. 2003;5(3)68-72.

21. Quinn GP, Jacobsen PB, Albrecht TL, Ellison BA, Newman NW, Bell M, et al. Real-time patient satisfaction survey and improvement process. Hosp Top. 2004;82(3): 26-32. 